\title{
Research on the Relation between Transformer Oil Flow Electrification and Electrostatic Current
}

\author{
Qiang Fu*, Rui Wang**, Pinguo Zou***, Zhao Li**, Yang Yang** and Xuejun Xie ${ }^{\dagger}$ \\ Abstract - In order to study and obtain the mathematical relation between the electrification degree \\ of transformer oil flow and the electrostatic current, a small amount of data about the electrification \\ degree of oil flow and the corresponding electrostatic current is studied by linear regression method \\ and grey model method. The results show that the linear correlation between the electrification degree \\ and the electrostatic current was not good, and the relation between the electrification degree of oil \\ flow and electrostatic current (i) could be expressed as $\rho^{(0)}=0.2049 \mathrm{i}^{(0)}+169.4419$ according to grey \\ model GM $(0,2)$ when the electrification degree of oil flow is represented by the charge number \\ generated from transformer oil per unit volume, namely the charge density $(\rho)$.
}

Keywords: Oil flow electrification, Electrostatic current, Grey model

\section{Introduction}

Oil Flow Electrification was a kind of electrification phenomenon that occurs on the surface of solid insulation or in the insulating oil, which was caused by the friction between the oil and the surface of the insulation structure components when the oil flows at a certain speed in the transformer. It could also be explained by electrostatic effect. The Electrification Degree of oil flow, namely the Charging Tendency, or Electrostatic Charging Tendency (ECT), represents the capability of generating electric charge when the transformer oil flows through the solid insulation surface under certain external conditions such as velocity of flow and pressure, and can be represented by charge density $(\rho)$, which means the charge number generated from per unit volume of transformer oil: $\rho=q / V$ ( $\mathrm{V}$ is the total volume of transformer oil, and $\mathrm{q}$ is the total charge number generated when oil flows through the solid insulation surface). And we often use $\mathrm{C} / \mathrm{m}^{3}, \mathrm{pC} / \mathrm{ml}$ or $\mathrm{pC} / \mathrm{cm}^{3}$ as the unit of Electrification Degree [1-6].

Through researches, scholars from all over the world hold the opinion that the electrification of transformer oil flow has a lot to do with the insulation structure of the transformer, oil flow velocity, oil temperature and charging tendency (electrification degree) of oil flow. At a certain flow velocity and under certain temperature, the electrification of oil flow may cause partial discharge of UHV power transformers and oil aging, which may lead to

$\dagger$ Corresponding Author: School of power and mechanical engineering, Wuhan University, Wuhan, China. (xiexuejun@163.com)

* Guangdong Power Grid Electric Power Science \& Research Institute, Guangzhou, China. (fuqiang7293@163.com)

** School of power and mechanical engineering, Wuhan University, Wuhan, China. (\{1193944478,596908993,1250108633\}@qq.com)

*** Central Southern China Electric Power Design Institute of China Power Engineering Consulting Group, Wuhan, China. (ystzhd $a$ 126.com)

Received: May 25, 2014; Accepted: October 29, 2014 operation accidents that mainly result from the damage of transformers due to electrostatic discharge caused by the electrification of oil flow.

At present, there are many researches covering the fields such as the major research methods and means of electrification of transformer oil flow, the mechanism and influence factors of the electrification, the impact on transformer oil caused by the electrification, and the malfunction caused by the electrification as well as the control measures. But there is hardly any research on the mathematical relation between the electrification degree of oil flow and the electrostatic current. Therefore, this article adopts the linear regression method and grey model theory to study the mathematical relation between the electrification degree of transformer oil flow and the electrostatic current.

Electrostatic current - i, is the electrostatic streaming current detected in oil or the electrostatic leakage current detected on solid insulation during the oil flow process. The total charge number - $\mathrm{q}$ could be expressed by the equation $\mathrm{q}=\int_{0}^{T}$ idt ( $\mathrm{T}$ means the time required for the oil flowing through the solid insulation), so the equation $\rho=\left(\int_{0}^{T} \mathrm{idt}\right) / \mathrm{V}$ means that the electrification degree of oil flow could be calculated by detecting the electrostatic current. Certainly, the definite relation between the electrification degree of oil flow and electrostatic current must be acquired before the calculation. That is to say, the mathematical expression of the relation between the electrification degree of oil flow and the electrostatic current must be researched [7-11].

There are many mathematical methods that can be used to study the mathematical expression of incidence relation, including linear mathematical methods such as regression analysis, variance analysis or other mathematical statistics methods, and nonlinear mathematical methods such as grey 
system theory. However, mathematical statistics methods such as regression analysis and variance analysis require large sample and good distribution pattern of the data, and the data processing and calculation process is complicated. Therefore, their application is limited. Compared to that, grey system theory needs less data ( $\geq 5$ groups) and calculation, which makes it possible to process finite and irregular data so as to find the internal characteristics of the system. As a result, grey model method is adopted to study the mathematical expression of the relation between the electrification degree of oil flow and the electrostatic current, while linear regression method is adopted to conduct comparison.

In order to study the mathematical expression of the relation between the electrification degree of oil flow and the electrostatic current, the electrification degree of oil flow and the electrostatic current of oil from two transformers in a transformer substation were found in literature [12-16].

\section{Research on the Relation between the Electrification Degree of Oil Flow and the Electrostatic Current by Linear Regression Mathmatical Method}

Using the Excel software to draw the relational graphs of the electrification degree and the electrostatic current of oil sample 1 and oil sample 2 respectively, and Figs. 1 and Fig. 2 were obtained.

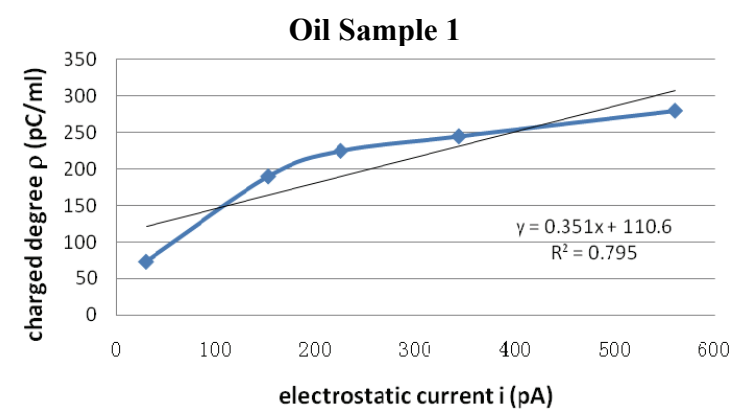

Fig. 1. The relational graph of the electrification degree and the electrostatic current of oil sample 1

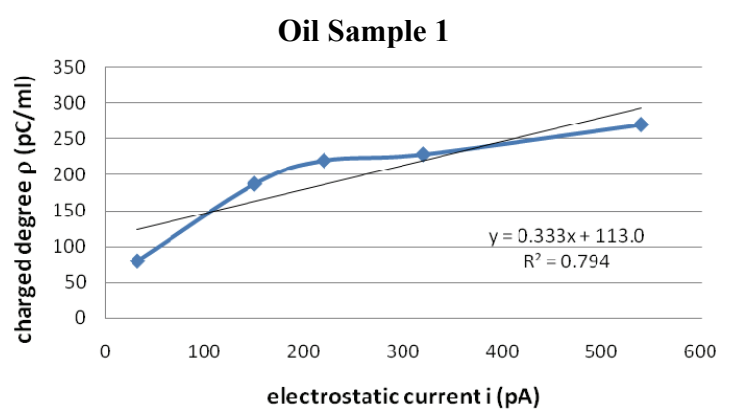

Fig. 2. The relational graph of the electrification degree and the electrostatic current of oil sample 2
Figs. 1 and Fig. 2 showed that the related coefficient of the electrification degree and the electrostatic current of oil sample 1 and oil sample 2 were both low.

\section{Research on the Relation between the Electrification Degree of Oil flow and the Electrostatic Current by Grey Model [17, 18]}

\subsection{Brief introduction of grey model}

\subsubsection{Grey System refers to a system with its information partly explicit. Grey System theory needs less data $(\geq$ 5 groups) and calculation, which makes it possible to process finite and irregular data so as to find the internal characteristics of the system.}

Model obtained from grey system is called GREY MODEL (GM). An nth-order GM with h variables should be denoted by GM $(n, h)$. It represents the influence of other (h-1) variables on the nth-order derivative of a variable, in which $\mathrm{n}$ represents the nth-order derivative of a variable, and could be $0,1,2,3 \ldots$ But generally it would not exceed 3 , because a bigger $n$ means richer connotation, and it would also be harder to solve the secular equation of a high-order system. Not only the calculation process is complicated and time-consuming, but also the accuracy is not necessarily high, and the result is not analytical. And h represents $h$ variables.

When the other factors of transformer and its oil are fixed, GM $(0, h)$ model could be used to study the relation between the electrification degree of transformer oil flow and the electrostatic current.

GM $(0, h)$ model refers to a 0 -order model with $\mathrm{h}$ variables. 0-order means no dynamical variables and the system is static. For the transformer and its oil system, when the other factors of the transformer and its oil are fixed, $\operatorname{GM}(0,2)$ model could be used to study the relation between the electrification degree of transformer oil flow and the electrostatic current.

\subsubsection{For the GM $(0, h)$ model, there is a differential equation, as in (1).}

$$
\begin{aligned}
& x_{1}^{(1)}=b_{1} x_{2}^{(1)}+b_{2} x_{3}^{(1)}+\ldots+b_{h-2} x_{h-1}^{(1)}+a \\
& \text { Define: } B=\left(\begin{array}{llll}
x_{2}^{(1)}(2) & \ldots & x_{h-1}^{(1)}(2) & 1 \\
x_{2}^{(1)}(3) & \ldots & x_{h-1}^{(1)}(3) & 1 \\
\ldots \\
x_{2}^{(1)}(N) & \ldots & x_{h-1}^{(1)}(N) & 1
\end{array}\right), \\
& \text { then }\left(\begin{array}{c}
x_{1}^{(1)}(2) \\
x_{1}^{(1)}(3) \\
\ldots \\
x_{1}^{(1)}(N)
\end{array}\right)=B\left(\begin{array}{c}
b_{1} \\
\ldots \\
b_{h-2} \\
a
\end{array}\right) .
\end{aligned}
$$


Define: $\hat{b}=\left[\mathrm{b}_{1}, \mathrm{~b}_{2}, \ldots, \mathrm{b}_{\mathrm{h}-2}, \mathrm{a}\right]^{\mathrm{T}}$, $\mathrm{y}_{\mathrm{N}}()=.\left[\mathrm{x}_{1}{ }^{(1)}(2), \mathrm{x}_{1^{(1)}}(3), \ldots, \mathrm{x}_{1^{(1)}}(\mathrm{N})\right]^{\mathrm{T}}$, then $\left(\begin{array}{c}\mathrm{b}_{1} \\ \cdots \\ \mathrm{b}_{\mathrm{h}-2} \\ \mathrm{a}\end{array}\right)=\left[\mathrm{B}^{\mathrm{T}} \mathrm{B}\right]^{-1} \mathrm{~B}^{\mathrm{T}} \mathrm{y}_{\mathrm{N}}($.

So the expression equation of GM $(0, \mathrm{~h})$ model is as in (2).

$$
x_{1}^{(1)}(i)=b_{1} x_{2}^{(1)}(i)+b_{2} x_{3}^{(1)}(i)+\ldots+b_{h-2} x_{h-1}^{(1)}(i)+a
$$

and $x_{i}^{(1)}(m)=\sum_{k=1}^{m} x_{i}^{(0)}(k), \quad m \leq N$.

\subsubsection{Modify the GM $(0, h)$ model properly to get linear} regression model by substituting $x_{i}^{(1)}(k)$ with $x_{i}^{(0)}(k)$. So the linear regression model is as in (3).

$$
\hat{x}_{1}^{(0)}(k)=\mathrm{b}_{1} x_{2}{ }^{(0)}(k)+\mathrm{b}_{2} x_{3}{ }^{(0)}(k)+\ldots+\mathrm{b}_{\mathrm{h}-2} x_{\mathrm{h}-1}{ }^{(0)}(k)+a
$$

The identification formulas of $a, b_{1}, b_{2}, \ldots, b_{h-2}$ and other parameters of the linear regression model are basically the same with the GM $(0, \mathrm{~h})$ model, except that $x_{i}^{(1)}(k)$ is replaced by $x_{\mathrm{i}}^{(0)}(k)$.

\subsubsection{The posteriori differential test method}

Posteriori differential test is based on residual error. The residual error of data $\mathrm{i}$ is defined as $\mathcal{E}^{(0)}(i)=x^{(0)}(i)-$ $\hat{x}^{(0)}(i), \quad i=1,2, \ldots, n$.

$x^{(0)}(i)$ is the ith initial data, and $\hat{x}^{(0)}(i)$ is the predicted value of the ith initial data.

The content of posteriori differential test is to examine the probability of occurrence of small residual error and the value of some related indicators of the residual error according to the value of $\varepsilon^{(0)}(i)$.

Data needed for the posteriori differential test include: the average value of the initial data $-\bar{x}=\frac{1}{N} \sum_{i=1}^{N} x^{(0)}(i)$ ( $\mathrm{N}$ means the number of the initial data), the variance of the initial data $-S_{2}{ }^{2}=\frac{1}{n} \sum_{i=1}^{n}\left(x^{(0)}(i)-\bar{x}\right)^{2}$, the average value of the residual error $-\bar{\varepsilon}=\frac{1}{n} \sum_{i=1}^{n} \varepsilon^{(0)}(i)$, the variance of the residual error $-S_{1}{ }^{2}=\frac{1}{n} \sum_{i=1}^{n}\left(\varepsilon^{(0)}(i)-\bar{\varepsilon}\right)^{2}$ (n means the number of the residual error and usually $\mathrm{n} \leq \mathrm{N}$ ), the ratio of the posteriori differential $-C=\frac{S_{1}}{S_{2}}$, and the probability of small residual error $-P=P\left\{\left(\varepsilon^{(0)}(i)-\bar{\varepsilon}\left(\prec 0.6745 S_{2}\right\}\right.\right.$.

A model with good extrapolation must have a small $\mathrm{C}$, because a small $\mathrm{C}$ means a small $\mathrm{S}_{2}$ and a big $\mathrm{S}_{1} . \mathrm{S}_{1}$ is the variance of the initial data, and the bigger it is, the more discrete the initial data will be, namely the regularity of the initial data will be poor. $S_{2}$ is the variance of the residual error, and a small $S_{2}$ means the residual error will be less discrete. Thus, a good model needs a big $\mathrm{S}_{1}$ and a small $\mathrm{S}_{2}$. As an aggregative indicator, the smaller $\mathrm{C}$ is the better. $\mathrm{A}$ small $\mathrm{C}$ means the residual error is less discrete, although the initial data is irregular. Ordinarily $\mathrm{C}<0.35$ or $<0.65$ is required.

Another indicator of good extrapolation is a big p. If residual error $\left|\varepsilon^{(0)}(i)-\bar{\varepsilon}\right|<0.6745 \mathrm{~S}_{2}$ or relative residual error $\left|\varepsilon^{(0)}(i)-\bar{\varepsilon}\right| / S_{2}<0.6745$, it could be called small error. It would be more reasonable to use relative residual error instead of residual error, because a bigger $S_{2}$ allows a bigger $\left|\mathcal{E}^{(0)}(i)-\bar{\varepsilon}\right|$. Generally $\mathrm{p}$ should be less than 0.95 and not below 0.7 .

According to the value of $\mathrm{p}$ and $\mathrm{C}$, the model could be divided into 4 precision levels just as showed in Table 1 .

Table 1. The value range of $\mathrm{p}$ and $\mathrm{C}$ for each level

\begin{tabular}{c|c|c}
\hline Precision Level & $\mathrm{p}$ & $\mathrm{C}$ \\
\hline Good & 0.95 & 0.35 \\
\hline Qualified & 0.8 & 0.5 \\
\hline Justmark & 0.7 & 0.65 \\
\hline Unqualified & 0.7 & 0.65 \\
\hline
\end{tabular}

3.1.5 If $x_{1}$ and $x_{2}$ respectively refer to the electrification degree of oil flow - $\rho$ and electrostatic current - $i$, the static model GM $(0,2)$ of $\rho$ and $i$ would be as in (4).

$$
\rho=b_{1} \mathrm{i}+a
$$

namely $\left(\begin{array}{c}\rho^{(1)}(2) \\ \rho^{(1)}(3) \\ \ldots \\ \rho^{(1)}(\mathrm{N})\end{array}\right)=\mathrm{B}\left(\begin{array}{l}\mathrm{b}_{1} \\ a\end{array}\right)$ with $B=\left(\begin{array}{ll}\mathrm{i}^{(1)}(2) & 1 \\ \mathrm{i}^{(1)}(3) & 1 \\ \ldots & \\ \mathrm{i}^{(1)}(N) & 1\end{array}\right)$,

$\hat{b}=\left(\begin{array}{l}b_{1} \\ a\end{array}\right)=\left[B^{T} B\right]^{-1} B^{T} y_{N}($.$) , and$

$\mathrm{y}_{\mathrm{N}}()=.\left[\rho^{(1)}(2), \quad \rho^{(1)}(3), \ldots, \quad \rho^{(1)}(\mathrm{N})\right]^{\mathrm{T}}$.

In the above equations, $x_{i}^{(1)}(\mathrm{m})=\sum^{\mathrm{m}} x_{i}^{(0)}(k), \mathrm{m} \leq \mathrm{N}$, and $\mathrm{N}$ is the number of factors of the electrostatic current studied.

\subsection{Calculation procedure}

Fig. 3 is the block diagram of the calculation procedure 


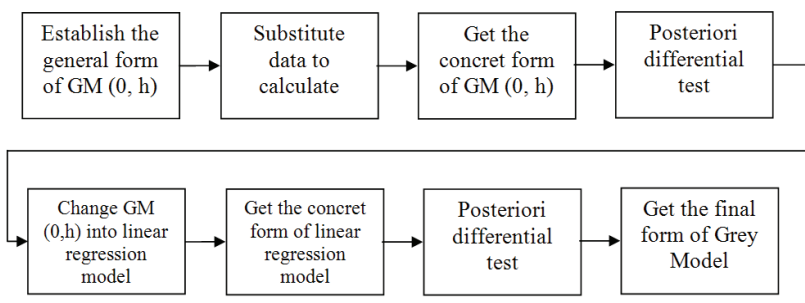

Fig. 3. The block diagram of the calculation procedure

for establishing a Grey Model. First of all, the general form of $\operatorname{GM}(0, h)$ is established, and the electrification degree of oil flow- $\rho$ and electrostatic current-i are substituted. Then the concrete form of $\operatorname{GM}(0, h)$ is obtained by calculation. After that, the posteriori differential test is conducted, and the accumulated value of the calculation results is compared with that of the measured results to inspect the precision and extrapolation of the model. Then, $\mathrm{GM}(0, \mathrm{~h})$ model is converted into linear regression model, and the concrete form of the linear regression model is obtained by calculation. Meanwhile, posteriori differential test is conducted, and the calculated value is compared with the measured value. According to the results above, the final Grey Model of the relation between the electrification degree of oil flow and the electrostatic current is obtained.

\subsection{The GM $(0,2)$ model of the relation between the electrification degree of oil flow and the elec- trostatic current}

The data of oil sample 1 was used to establish the concrete form of the $\operatorname{GM}(0,2)$ model of the relation between the electrification degree of oil flow and the electrostatic current. Then, the data of oil sample 2 was used to test and verify the accuracy of the $\operatorname{GM}(0,2)$ model.

As usual, the general form of $\operatorname{GM}(0,2)$ was

$\rho^{(1)}{ }_{(\text {oil sample } 1)}=\mathrm{b}_{1 \mathrm{i}}{ }^{(1)}+a$.

For oil sample 1,

$$
\begin{aligned}
& y_{5}(.)=\left[\rho^{(1)}(2) \quad \rho^{(1)}(3) \rho^{(1)}(4)\right. \\
& \left.\rho^{(1)}(5)\right]^{\mathrm{T}}=\left[\begin{array}{llll}
263 & 488 & 733 & 1013
\end{array}\right]^{\mathrm{T}} \text {, } \\
& B=\left(\begin{array}{ll}
i^{(1)}(2) & 1 \\
i^{(1)}(3) & 1 \\
i^{(1)}(4) & 1 \\
i^{(1)}(5) & 1
\end{array}\right)=\left(\begin{array}{ll}
181.2 & 1 \\
406.2 & 1 \\
749.2 & 1 \\
1309.2 & 1
\end{array}\right) \text {, so } \\
& \mathrm{B}^{\mathrm{T}}=\left(\begin{array}{cccc}
181.2 & 406.2 & 749.2 & 1309.2 \\
1 & 1 & 1 & 1
\end{array}\right), \\
& \mathrm{B}^{\mathrm{T}} \mathrm{B}=10^{6}\left(\begin{array}{ll}
2.4731 & 0.0026 \\
0.0026 & 0.0000
\end{array}\right) \text {, } \\
& \hat{b}=\left[\mathrm{B}^{\mathrm{T}} \mathrm{B}\right]^{-1} \mathrm{~B}^{\mathrm{T}}, y_{\mathrm{N}}(.)=\left[\mathrm{B}^{\mathrm{T}} \mathrm{B}\right]^{-1} \mathrm{~B}^{\mathrm{T}}, \quad y_{5}(.)=\left(\begin{array}{c}
0.6495 \\
194.6492
\end{array}\right) \text {, } \\
& \rho^{(1)}{ }_{(\text {Oil sample } 1)}=0.6495 \mathrm{i}^{(1)}+194.6492
\end{aligned}
$$

3.4 The examination of the GM $(0,2)$ model of the relation between the electrification degree of oil flow and the electrostatic current

\subsubsection{The posteriori differential test}

$$
\begin{aligned}
& \varepsilon(1)=-140.6, \varepsilon(2)=-49.3, \varepsilon(3)=29.5, \varepsilon(4)=51.8, \\
& \varepsilon(5)=-32, \text { then } \bar{\varepsilon}=\frac{1}{5} \sum_{k=1}^{5} \varepsilon(k)=-28.12 \\
& (\varepsilon(1)-\bar{\varepsilon})^{2}=(-112.48)^{2},(\varepsilon(2)-\bar{\varepsilon})^{2}=(-21.18)^{2}, \\
& (\varepsilon(3)-\bar{\varepsilon})^{2}=(57.62)^{2},(\varepsilon(4)-\bar{\varepsilon})^{2}=(79.92)^{2}, \\
& (\varepsilon(5)-\bar{\varepsilon})^{2}=(-3.88)^{2}, \text { then } \\
& S_{1}^{2}=\frac{1}{5} \sum_{k=1}^{5}(\varepsilon(k)-\bar{\varepsilon})^{2}=4564.534, \text { and } \mathrm{S}_{1}=67.56133 . \\
& \bar{\rho}=\frac{1}{5} \sum_{k=1}^{5} \rho^{(1)}(k)=514,\left(\rho^{(1)}(1)-\bar{\rho}\right)^{2}=(-441)^{2}, \\
& \left(\rho^{(1)}(2)-\bar{\rho}\right)^{2}=(-251)^{2},\left(\rho^{(1)}(3)-\bar{\rho}\right)^{2}=(-26)^{2}, \\
& \left(\rho^{(1)}(4)-\bar{\rho}\right)^{2}=(219)^{2},\left(\rho^{(1)}(5)-\bar{\rho}\right)^{2}=(499)^{2}, \text { then } \\
& S_{2}^{2}=\frac{1}{5} \sum_{k=1}^{5}\left(\rho^{(1)}(k)-\bar{\rho}\right)^{2}=111024, \text { and } \mathrm{S}_{2}=333.2026, \\
& 0.6745 \mathrm{~S}_{2}=224.7452537 . \\
& \text { So, } C=\frac{S_{1}}{S_{2}}=\frac{67.56133}{333.2026}=0.202763<0.35, \\
& P=P\left\{|\varepsilon(k)-\bar{\varepsilon}|<0.6745 \mathrm{~S}_{2}\right\}=1>0.95, \text { and the precision } \\
& \text { level of the model was GOOD. }
\end{aligned}
$$

\subsubsection{Formula $\rho^{(1)}{ }_{(\text {Oil sample } 1)}=0.6495 \mathrm{i}^{(1)}+194.6492$ was used to calculate the accumulated value of the electrification degree of oil sample 1 and oil sample 2, and the data is showed in Table 2.}

Thus it can be seen that the precision level of the GM $(0$, 2) model of the relation between the electrification degree of oil flow and the electrostatic current is "GOOD". Combining with the comparative result between the calculated value of $\rho^{(1)}$ and the accumulated real value of $\rho$, the $\operatorname{GM}(0,2)$ model of the electrification degree of oil flow and the electrostatic current could be initially expressed as in (5).

$$
\rho^{(1)}=0.6495 \mathrm{i}^{(1)}+194.6492
$$

\subsection{Convert the GM $(0,2)$ model into linear regression model and test it}

The linear regression model $\rho^{(0)}$ (oil sample 1) $=0.2049 \mathrm{i}^{(0)}+$ 169.4419 was obtained from $\rho^{(1)}{ }_{\text {(oil sample } 1)}=0.6495 \mathrm{i}^{(1)}+$ 194.6492. As $\mathrm{P}=0.8>0.7,0.5<\mathrm{C}=0.584926<0.65$, the precision level of the linear regression model was JUSTMARK. 
Table 2. The electrification degree and electrostatic current of oil samples (sample 1 and sample 2) from two transformers in a substation

\begin{tabular}{|c|c|c|c|c|c|c|c|c|c|c|}
\hline & \multicolumn{5}{|c|}{ Oil sample 1} & \multicolumn{5}{|c|}{ Oil sample 2} \\
\hline $\mathrm{i}^{(0)}(\mathrm{m})(\mathrm{pA})$ & 29.2 & 152.0 & 225.0 & 343.0 & 560.0 & 32.0 & 150.0 & 220.0 & 320.0 & 540.0 \\
\hline $\mathrm{i}^{(1)}(\mathrm{m})(\mathrm{pA})$ & 29.2 & 181.2 & 406.2 & 749.2 & 1309.2 & 32.0 & 182.0 & 402.0 & 722.0 & 1262.0 \\
\hline$\rho^{(0)}(\mathrm{m})(\mathrm{pC} / \mathrm{ml})$ & 73.0 & 190.0 & 225.0 & 245.0 & 280.0 & 80.0 & 187.5 & 220 & 228.6 & 270 \\
\hline $\pm 10 \% \rho^{(0)}(\mathrm{m})(\mathrm{pC} / \mathrm{ml})$, & 65.7 & 171.0 & 202.5 & 220.5 & 252.0 & 72.0 & 168.8 & 198.0 & 205.7 & 243.0 \\
\hline & 80.3 & 209.0 & 247.5 & 269.5 & 308.0 & 88.0 & 206.3 & 242.0 & 251.5 & 297.0 \\
\hline$\rho^{(0)}(\mathrm{m})(\mathrm{pC} / \mathrm{ml}$, calcul-ated value $)$ & 175.4 & 200.6 & 215.5 & 239.7 & 284.2 & $\ldots$ & $\ldots$ & $\ldots$ & $\ldots$ & $\ldots$ \\
\hline$\rho^{(0)}(\mathrm{m})(\mathrm{pC} / \mathrm{ml}$,predicted value of oil sample 2$)$ & $\ldots$ & $\ldots$ & $\ldots$ & $\ldots$ & $\ldots$ & 176.0 & 200.2 & 214.5 & 235.0 & 280.1 \\
\hline$\rho^{(1)}(\mathrm{m})(\mathrm{pC} / \mathrm{ml})$ & 73.0 & 263.0 & 488.0 & 733.0 & 1013.0 & 80.0 & 267.5 & 487.5 & 716.1 & 986.1 \\
\hline $\pm 10 \% \rho^{(1)}(\mathrm{m})(\mathrm{pC} / \mathrm{ml})$ & $\begin{array}{l}65.7 \\
803\end{array}$ & 236.7 & $\begin{array}{l}439.2 \\
5368\end{array}$ & 659.7 & 911.7 & 72.0 & 240.8 & 438.8 & 644.5 & 887.5 \\
\hline$\rho^{(1)}(\mathrm{m})(\mathrm{pC} / \mathrm{ml}$, calcul-ated value $)$ & 213.6 & 312.3 & 458.5 & 681.2 & 1045.0 & $\ldots$ & $\ldots$ & $\ldots$ & $\ldots$ & $\ldots$ \\
\hline $\begin{array}{c}\rho^{(1)}(\mathrm{m})(\mathrm{pC} / \mathrm{ml}, \text { accumulated predicted value of oil } \\
\text { sample } 2)\end{array}$ & $\ldots$ & $\ldots$ & $\ldots$ & $\ldots$ & $\ldots$ & 215.4 & 312.9 & 455.8 & 663.6 & 1014.3 \\
\hline
\end{tabular}

$\left[\mathrm{i}^{(0)}\right.$ and $\rho^{(0)}$ respectively represent the measured value of electrostatic current and electrification degree of oil, $\mathrm{i}^{(1)}$ and $\rho^{(1)}$ respectively represent the accumulated value of measured value, namely, $\left.\quad \mathrm{i}^{(1)}(\mathrm{k})=\sum_{\mathrm{k}} \mathrm{i}^{(0)}(\mathrm{k}), \quad \rho^{(1)}(\mathrm{k})=\sum_{\mathrm{k}} \rho^{(0)}(\mathrm{k}), \quad k=1,2,3,4\right]$

$$
\begin{aligned}
& \text { Since } B=\left(\begin{array}{ll}
i^{(0)}(2) & 1 \\
i^{(0)}(3) & 1 \\
i^{(0)}(4) & 1 \\
i^{(0)}(5) & 1
\end{array}\right)=\left(\begin{array}{ll}
152 & 1 \\
225 & 1 \\
343 & 1 \\
560 & 1
\end{array}\right) \text {, } \\
& \hat{b}=\left[\mathrm{B}^{\mathrm{T}} \mathrm{B}\right]^{-1} \mathrm{~B}^{\mathrm{T}} \mathrm{y}_{\mathrm{i}}(.)=\left[\mathrm{B}^{\mathrm{T}} \mathrm{B}\right]^{-1} \mathrm{~B}^{\mathrm{T}} \mathrm{y}_{5}(.)=\left(\begin{array}{c}
0.2049 \\
169.4419
\end{array}\right) \text {, } \\
& \mathrm{S}_{1}=41.56426 \text {, } \\
& y_{i}(.)=y_{5}(.) \\
& =\left[\begin{array}{llll}
\rho^{(0)}(2) & \rho^{(0)}(3) & \rho^{(0)}(4) & \rho^{(0)}(5)
\end{array}\right]^{\mathrm{T}} \\
& =\left[\begin{array}{llll}
190 & 225 & 245 & 280
\end{array}\right]^{\mathrm{T}} \text {, } \\
& \mathrm{S}_{2}=71.0566 \text {, and } 0.6745 \mathrm{~S}_{2}=47.9276767(k=1,2,3,4,5) \text {. }
\end{aligned}
$$

The data of the electrification degree of the oil flow calculated from the linear regression model is also showed in Table 2.

The posteriori differential test showed that the precision level of the linear regression model was JUSTMARK. By comparing the accumulated calculated value of $\rho^{(0)}$ with the accumulated measured value of $\rho$, the errors of 80 percent of the results are smaller than $10 \%$ and the rest are quite big.

\section{Conclusion}

The data of the electrification degree of transformer oil flow and the electrostatic current were studied by linear regression method and grey model method. The results showed that the linear correlation between the electrifycation degree and the electrostatic current was not good, and according to grey model $\mathrm{GM}(0,2)$, the relation between the electrification degree of oil and the electrostatic current could be expressed as in (6).

$$
\rho^{(0)}=0.2049 \mathrm{i}(0)+169.4419
$$

\section{References and Notes}

[1] M. Zdanowski, "Influence of composition of dielectric liquid mixtures on electrostatic charge tendency and physicochemical parameters," IEEE Transactions on dielectrics and eleetrical insulation, vol. 15, no. 2, pp. 527-532, 2008.

[2] M. Zdanowski, J. Kedzia, "Research on the electrostatic properties of liquid dielectric mixtures," Journal of electrostatics, vol. 65 , no. 8, pp. 506-510, 2007.

[3] D. O. Zmarzly, J. Kedzia, "A noise analyzer for monitoring static electrification current," Journal of electrostatics, vol. 63, no. 5, pp. 409-422, 2005.

[4] E. Moreau, T. Paillat, G. Touchard, "Flow electrification in high power transformers: BTA effect on pressboard degraded by electrical discharges," IEEE transactions on dielectrics and eleetrical insulation, vol. 10, no. 1 pp. 15-21, 2003

[5] M. Zdanowski, "Streaming electrification of mineral insulating oil and synthetic ester MIDEL 7131(R)," IEEE transactions on dielectrics and electrical insulation, vol. 21, no. 3, pp. 1127-1132, 2014.

[6] M. Talhi, I. Fofana, S. Flazi, "Comparative study of the electrostatic charging tendency between synthetic ester and mineral oil," IEEE transactions on dielectrics and electrical insulation, vol. 20, no. 5, pp. 1598-1606, 2013.

[7] D. O. Zmarzly, "Streaming electrification measurements in swinging cylinder system," IEEE transactions on dielectrics and electrical insulation, vol. 19, no. 5, pp. 1665-1672, 2012.

[8] P. Aksamit, D. Zmarzly, T. Boczar, "Electrostatic properties of aged fullerene-doped mineral oil," IEEE transactions on dielectrics and electrical insulation, vol. 18, no. 5, pp. 1459-1462, 2011.

[9] K. Jozef, Z. Dariusz, A. Pawel, "Research on streaming electrification of transformer oils," Przeglad 
elektrotechniczny. vol. 86, no. 11B, pp. 244-246, 2010.

[10] T. Paillat, Y. Zelu, G. Morin, C. Perrier, "Ester oils and flow electrification hazards in power transformers," IEEE transactions on dielectrics and electrical insulation. vol. 19 no. 5, pp. 1537-1543, 2012

[11] M. Zdanowski, S. Wolny, D. O. Zmarzly, T. Boczar, "ECT of ethanol and hexane mixtures in the spinning disk system," Journal of electrostatics. vol. 65, no. 4, pp. 239-243, 2007

[12] I. Fofana, Y. Bouslimi, H. Hemmatjou, C. Volat, K. Tahiri, "Relationship between static electrification of transformer oils with turbidity and spectrophotometry measurements," International journal of electrical power \& energy systems, vol. 54, pp. 38-44, 2014

[13] T. Paillat, P. Mas, O. Moreau, G. Touchard, "Flow electrification in transformers: relevance of ECT and leakage current measurements," IEEE transactions on dielectrics and electrical insulation, vol. 10, no. 1, pp. 7-14, 2003

[14] J. C. Wang, "Study on the measurement method for the transformer oil flow electrification." Shandong University, 2007.

[15] T. J. Harvey, R. J. K. Wood, G. Denuault, H. E. G. Powrie, "Effect of oil quality on electrostatic charge generation and transport," Journal of electrostatics. vol. 55, no. 1, pp. 1-23, 2002

[16] Z. Dariusz, "Streaming electrification current model in a round pipe in turbulent regime," IEEE transactions on dielectrics and electrical insulation, vol. 20, no. 5, pp. 1497-1509, 2013.

[17] J. L. Deng, “Grey control system,'Wuhan: Huazhong University of science and technology, 1993, p. 492.

[18] J. L. Deng, "Grey forecasting and decision-making," Wuhan: Huazhong University of science and technology, 1988, p. 325.

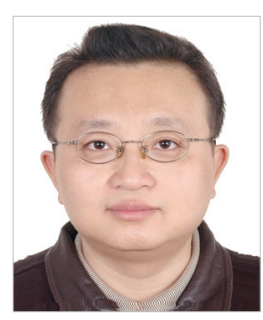

Qiang Fu He received Master's degree in applied chemistry from Wuhan University. His research interest is electric power chemistry.

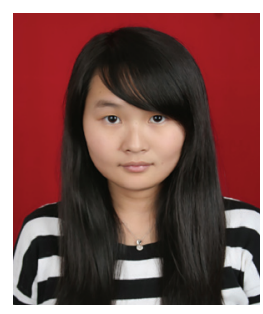

Rui Wang She received B. S degree in applied chemistry from Wuhan University. Her research interest is electric power chemistry.

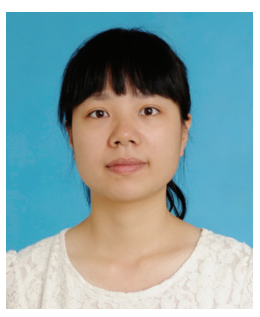

Pinguo Zou She received Master's degree in applied c-hemistry from Wuhan university. Herresearch interest is electric power chemistry.

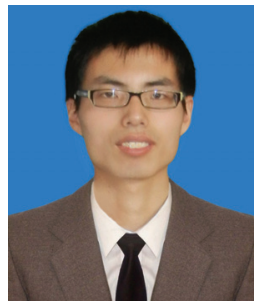

Zhao Li He received B. S degree in applied chemistry from Wuhan University. His research interest is electric power chemistry.

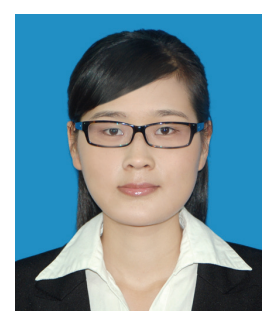

Yang Yang She received B. S degree in applied chemistry from Wuhan University. Her research interest is electric power chemistry.

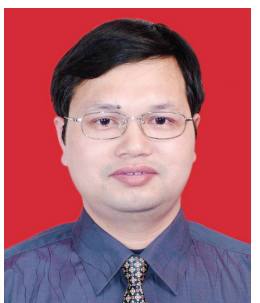

Xuejun Xie He received Doctor's degree in applied chemistry from Wuhan University. His research interest is electric power chemistry. 